\title{
Geographic trends of scientific output and citation practices in psychiatry
}

\author{
Artemis Igoumenou ${ }^{1 *}$, Klaus Ebmeier ${ }^{2}$, Nia Roberts ${ }^{3}$ and Seena Fazel ${ }^{2}$
}

\begin{abstract}
Background: Measures of research productivity are increasingly used to determine how research should be evaluated and funding decisions made. In psychiatry, citation patterns within and between countries are not known, and whether these differ by choice of citation metric.

Method: In this study, we examined publication characteristics and citation practices in articles published in 50 Web of Science indexed psychiatric and relevant clinical neurosciences journals, between January 2004 and December 2009 comprising 51,072 records that produced 375,962 citations. We compared citation patterns, including self-citations, between countries using standard $x^{2}$ tests.
\end{abstract}

Results: We found that most publications came from the USA, with Germany being second and UK third in productivity. USA articles received most citations and the highest citation rate with an average 11.5 citations per article. The UK received the second highest absolute number of citations, but came fourth by citation rate ( 9.7 citations/article), after the Netherlands (11.4 citations/article) and Canada (9.8 citations/article).

Within the USA, Harvard University published most articles and these articles were the most cited, on average 20.0 citations per paper. In Europe, UK institutions published and were cited most often. The Institute of Psychiatry/Kings College London was the leading institution in terms of number of published records and overall citations, while Oxford University had the highest citation rate (18.5 citations/record).

There were no differences between the self-citation practices of American and European researchers. Articles that examined some aspect of treatment in psychiatry were the most published. In terms of diagnosis, papers about schizophrenia-spectrum disorders were the most published and the most cited.

Conclusions: We found large differences between and within countries in terms of their research productivity in psychiatry and clinical neuroscience. In addition, the ranking of countries and institutions differed widely by whether productivity was assessed by total research records published, overall citations these received, or citations per paper. The choice of measures of scientific output could be important in determining how research output translates into decisions about resource allocation.

Keywords: Scientific output, Citation practices, Psychiatry

\section{Background}

Citation practices differ widely within and between countries, while citation rates are increasingly used by funding agencies, universities, and governments to determine grants, career pathways, and the scientific impact of individuals, research groups, and countries $[1,2]$. Within

\footnotetext{
* Correspondence: a.igoumenou@gmul.ac.uk

${ }^{1}$ Violence Prevention Research Unit, Wolfson Centre of Preventive Medicine,

Barts and the London School of Medicine and Dentistry, Queen Mary,

University of London, Garrod Building, Turner Street, London E1 2AD,

England

Full list of author information is available at the end of the article
}

psychiatry, there has been research on local, national and international scientific productivity focusing on specific subspecialties and the most popular research areas within them [3-11], on individual institutions [12-14], journals $[15,16]$, the contribution of different countries $[8,17]$, practices [18] and early recognition of high quality researchers $[19,20]$. However, there has been little research examining trends in citation practice [21]. There are two reasons why examining citation trends is important. First, in determining how research should be evaluated, there are various models that need testing against each other. In 
some countries, it has been shown that there is a correlation between direct peer review of research groups and research bibliometrics [22] but this needs further examination within fields and between different bibliometric measures. Second, the practice of targeted self-citation is contentious, as it can be used to boost impact. Within some psychiatric subspecialties, it has been suggested that US authors disproportionately self-cite and cite colleagues from US institutions $[23,24]$, a trend also reported in the wider scientific literature [25]. Furthermore, in general medicine [26] and in some specialties [27] it has been shown that US authors cite UK authors less often than UK authors cite US authors. We sought to examine whether these patterns are found in the field of psychiatric research.

\section{Methods}

We examined publication characteristics and citation practices in articles published in 50 Web of Science indexed psychiatric and relevant clinical neurosciences journals, between January 2004 and December 2009. A time period of 5 years was considered to be long enough to provide a large number of articles. We collected our data in 2011; hence we allowed publications at least 2 years to receive citations. We selected all journals that have the root "psychiatr" in the title $(n=34)$, as we wanted to exclude research published in other scientific fields such as neurology or neurosurgery. As not all psychiatric journals included reference to "psychiatry" in the title, we searched for all further journals that belonged to the categories of neurosciences, behavioural sciences, and psychiatry and extracted data of a further 16 general journals in these fields (Table 1). We chose to use Web of Science (within the Web of Knowledge), because of its potential to systematically provide data for informetric analysis, including publication and citation analysis, as well as the fact that it comprehensively includes databases, such as the Science Citation Index, the Social Sciences Citation Index, the Journal Citation Reports, and the Essential Sciences Indicators [4].

At the time of our collection of data and analysis, the Web of Science did not provide the facility for direct analysis of citation practices in large datasets; hence we used HistCite, a complementary tool. We extracted all relevant articles with their references, citations and authors' affiliations from Web of Science and imported the data into a software tool for informetric analysis of citation linkage, HistCite. HistCite provides citation linkage between scientific papers with tables and graphs that assist visualising the flow of publications and citations within a scientific field $[4,28]$. Using HistCite, we identified numbers of scientific publications for countries and institutions, characteristics of papers that attract more or fewer citations, and the flow of citations between different scientific publications.
With regard to institutions and countries that produce publications or receive citations, HistCite analyses data collected from the address field of the records in Web of Science. Institutions and countries, therefore, represent the affiliation of the corresponding author. As some of the institutions consist of a number of subdivisions, hence different authors' affiliations, we explored whether institutions subsumed into greater local units were more productive and if their research was cited more often than others. We included all article types, such as original research, abstracts, reviews, and letters, taking into consideration that some article types attract more citations than others.

To examine citations practices amongst different countries and institutions, we used the Global Citation Score (GCS), which represents the total number of citations as given by Web of Science. From the GCS we also calculated the average number of citations per paper. Many measures have been used to quantify an individual researcher's citation impact, some of which provide also information about the quality of the publications, such as the h-index and the g-index [29-31]. We chose the GCS over other metrics as we focused on the scientific productivity and impact at country and university level rather than at researcher level. A major advantage of the GCS scores is that they are readily available from the Web of Science, as is the h-index. Citations are, of course, only one measure of scientific impact and do not distinguish between the quality of the publication, the impact of the journal citing and whether the citation is positive or negative. Citations have some of the limitations of the other measures of academic output. As with other measures, citations can be magnified or deflated according to researchers productivity concerning articles included in WoS database [31], their scientific collaborations and can be influenced by individuals in the same institution or group of institutions citing each other. Citations can potentially be exposed to errors due to articles being cited in different ways, variations in author affiliations or multiple author affiliations, and variations in institutional naming or indeed omission of country/institute of origin [32,33].

As HistCite does not automatically provide information about the details of citation practices, such as the distribution of citations between countries and institutions, and the number of self-citations, we extracted this information manually in a stratified sample of 1000 records. In order to gain representation of our initial sample of 51,072 articles, we collected the first 500 articles from the USA (as presented on HistCite in chronological order), and equally the first 500 articles from Europe (200 records from UK, 200 from Germany and 100 from other European countries). We sampled the earliest articles included in our initial search, as they had a better chance to generate citations since being published. For the purposes of 
Table 1 Journals included in the citation analyses according to total number of records published and total number of citations received (total global citation score, TGCS)

\begin{tabular}{|c|c|c|c|}
\hline \# & Journal & Records & TGCS \\
\hline 1 & Biological Psychiatry & 6037 & 46779 \\
\hline 2 & European Psychiatry & 4231 & 3764 \\
\hline 3 & $\begin{array}{l}\text { Journal of Neurology, Neurosurgery and } \\
\text { Psychiatry }\end{array}$ & 3502 & 21992 \\
\hline 4 & American Journal of Psychiatry & 2830 & 44413 \\
\hline 5 & Nervenarzt & 2419 & 1697 \\
\hline 6 & Psychiatric Services & 2206 & 8115 \\
\hline 7 & Journal of Clinical Psychiatry & 2094 & 24443 \\
\hline 8 & Psychopharmacology & 1971 & 27031 \\
\hline 9 & British Journal of Psychiatry & 1912 & 16435 \\
\hline 10 & Addiction & 1721 & 13910 \\
\hline 11 & $\begin{array}{l}\text { Australian and New Zealand Journal } \\
\text { of Psychiatry }\end{array}$ & 1628 & 5031 \\
\hline 12 & Acta Psychiatrica Scandinavica & 1615 & 8006 \\
\hline 13 & $\begin{array}{l}\text { Progress in Neuro-Psychopharmacology } \\
\text { \& Biological Psychiatry }\end{array}$ & 1147 & 8919 \\
\hline 14 & CNS Spectrums & 1064 & 3851 \\
\hline 15 & Pharmacopsychiatry & 1001 & 2904 \\
\hline 16 & International Journal of Geriatric Psychiatry & 974 & 6549 \\
\hline 17 & Psychiatry Research & 863 & 6829 \\
\hline 18 & Nervenheilkunde & 827 & 572 \\
\hline 19 & Canadian Journal of Psychiatry & 815 & 3516 \\
\hline 20 & Archives of General Psychiatry & 806 & 32233 \\
\hline 21 & Psychiatry and Clinical Neurosciences & 806 & 2646 \\
\hline 22 & Journal of Child Psychology and Psychiatry & 704 & 11167 \\
\hline 23 & Molecular Psychiatry & 680 & 19618 \\
\hline 24 & Nordic Journal of Psychiatry & 666 & 1078 \\
\hline 25 & American Journal of Geriatric Psychiatry & 665 & 6794 \\
\hline 26 & Psychosomatics & 604 & 2704 \\
\hline 27 & Fortschritte der Neurologie Psychiatrie & 598 & 785 \\
\hline 28 & Journal of Psychiatric Research & 544 & 6023 \\
\hline 29 & Current Opinion in Psychiatry & 470 & 3313 \\
\hline 30 & General Hospital Psychiatry & 466 & 3086 \\
\hline 31 & CNS Drugs & 453 & 5104 \\
\hline 32 & $\begin{array}{l}\text { International Journal of Psychiatry in } \\
\text { Clinical Practice }\end{array}$ & 450 & 410 \\
\hline 33 & Neuropsychobiology & 424 & 2834 \\
\hline 34 & Psychiatry-Research Neuroimaging & 403 & 4772 \\
\hline 35 & Comprehensive Psychiatry & 394 & 2647 \\
\hline 36 & $\begin{array}{l}\text { European Archives of Psychiatry and } \\
\text { Clinical Neuroscience }\end{array}$ & 371 & 3420 \\
\hline 37 & Psychopathology & 285 & 1358 \\
\hline 38 & Verhaltenstherapie & 258 & 342 \\
\hline
\end{tabular}

Table 1 Journals included in the citation analyses according to total number of records published and total number of citations received (total global citation score, TGCS) (Continued)

\begin{tabular}{|c|c|c|c|}
\hline 39 & Neurocase & 252 & 1190 \\
\hline 40 & Journal of Psychiatry \& Neuroscience & 240 & 2641 \\
\hline 41 & Archives of Psychiatric Nursing & 228 & 507 \\
\hline 42 & Perspectives in Psychiatric Care & 216 & 293 \\
\hline 43 & International Journal of Psychiatry in Medicine & 209 & 741 \\
\hline 44 & World Journal of Biological Psychiatry & 172 & 1095 \\
\hline 45 & World Psychiatry & 170 & 552 \\
\hline 46 & Journal of Geriatric Psychiatry and Neurology & 165 & 1324 \\
\hline 47 & Neuropsychiatrie & 151 & 401 \\
\hline 48 & Neurology Psychiatry and Brain Research & 148 & 85 \\
\hline 49 & $\begin{array}{l}\text { International Journal of Methods in Psychiatric } \\
\text { Research }\end{array}$ & 132 & 1952 \\
\hline 50 & Primary Care and Community Psychiatry & 85 & 82 \\
\hline
\end{tabular}

this sub-study, we used the Local Citation Score (LCS), which is the number of citations that a paper received within the field of psychiatry. Since research collaboration between countries is an increasing phenomenon, we also investigated the proportion of the publications in our sample that resulted from such collaboration. In a sensitivity analysis we combined Canada with the US (500 articles) to make North America and we investigated citation practices in North America and Europe.

We furthermore attempted to identify subject trends by examining the most common key words in the titles of publications. HistCite automatically generates results on the most common key words as they were identified by the article authors.

We investigated the following questions: Which country publishes more and which country's research attracts most citations? What are the world's top ten institutes in psychiatry in terms of publication productivity? What are the subjects in psychiatry that generate more publications? Who cites whom in psychiatry (self citations, within and between countries citation trends)? We used standard $\chi^{2}$ tests to test for differences between proportions.

\section{Results}

The 50 included psychiatric journals published a total of 51,072 articles between January 2004 and January 2009, most of which ( $n=46,984,92 \%)$ were published in English. These articles were written by 82,092 authors.

We found that most publications came from the USA, with Germany being second and UK third in publication productivity (Table 2). It was also evident that when counting the total number of citations (Total Global Citation Scores or TGCSs), USA articles received most citations and the highest citation rate with an average 
Table 2 Rankings in psychiatry/neurosciences ordered by total number of citations received (total global citation score, TGCS) (ranking in brackets)

\begin{tabular}{lllll}
\hline$\#$ & Country & TGCS & Records & Citations/paper \\
\hline 1 & USA & $202781(1)$ & $17610(1)$ & $11.5(1)$ \\
2 & UK & $62486(2)$ & $6468(3)$ & $9.7(4)$ \\
3 & Germany & $35526(3)$ & $7095(2)$ & $5.0(9)$ \\
4 & Canada & $24041(4)$ & $2451(5)$ & $9.8(3)$ \\
5 & Netherlands & $19206(5)$ & $1686(7)$ & $11.4(2)$ \\
6 & Australia & $17734(6)$ & $2192(6)$ & $8.1(6)$ \\
7 & Italy & $14476(7)$ & $1568(9)$ & $9.2(5)$ \\
8 & Japan & $10341(8)$ & $1616(8)$ & $6.4(8)$ \\
9 & Switzerland & $9643(9)$ & $1377(10)$ & $7.0(7)$ \\
10 & Unknown & $3733(10)$ & $4855(4)$ & $0.8(10)$ \\
\hline \multirow{2}{*}{$\begin{array}{l}2 \\
5\end{array}$} & & &
\end{tabular}

11.5 citations per article. The UK received the second highest absolute number of citations, but came fourth by citation rate (9.7 citations/article), after the Netherlands (11.4 citations/article) and Canada (9.8 citations/article).

Both globally and within the USA, Harvard University published most articles and these articles were the most cited, on average 20.0 citations per paper (see Table 3 for the top ten world institutions and Table 4 for the top ten USA institutions in terms of the citations received).

In Europe, UK institutions published and were cited most often. We found that the Institute of Psychiatry/ Kings College London was the leading institution in terms of number of published records and overall citations, while Oxford University had the highest citation rate (18.5 citations/record; Table 5 for the ranking of the top ten European research institutions and Table 6 for the ranking of the top ten UK research institutions).

We explored whether institutions subsumed into greater local units were more productive and if their research was

\begin{tabular}{|c|c|c|c|c|}
\hline$\overline{\#}$ & Institution & TGCS & Records & Citations/paper \\
\hline 1 & Harvard Univ & $38910(1)$ & $1948(1)$ & $20.0(1)$ \\
\hline 2 & Inst Psychiatry & $16730(2)$ & $1346(2)$ & $12.4(8)$ \\
\hline 3 & Univ Pittsburg & $15420(3)$ & $970(3)$ & $15.9(6)$ \\
\hline 4 & Yale Univ & $14633(4)$ & $894(4)$ & $16.4(4)$ \\
\hline 5 & Columbia Univ & $14381(6)$ & $882(5)$ & $16.3(5)$ \\
\hline 6 & $\mathrm{NIMH}$ & $14451(5)$ & $810(6)$ & $17.8(2)$ \\
\hline 7 & Toronto Univ & $8408(9)$ & $743(7)$ & $11.3(9)$ \\
\hline 8 & Univ Calif Los Angeles & $12634(7)$ & $741(8)$ & $17.1(3)$ \\
\hline 9 & Univ Calif San Diego & $9942(8)$ & $716(9)$ & $13.9(7)$ \\
\hline 10 & Univ Munich & $6010(10)$ & $651(10)$ & $9.2(10)$ \\
\hline
\end{tabular}

Table 4 Rankings of USA research institutions ordered by total number of citations received (total global citation score, TGCS) (ranking in brackets)

\begin{tabular}{lllll}
\hline$\#$ & Institution & TGCS & Records & Citations/paper \\
\hline 1 & Harvard Univ & $38910(1)$ & $1948(1)$ & $20.0(1)$ \\
2 & Univ Pittsburg & $15420(2)$ & $970(2)$ & $15.9(9)$ \\
3 & Yale Univ & $14633(3)$ & $894(3)$ & $16.4(5)$ \\
4 & NIMH & $14451(4)$ & $810(5)$ & $17.8(2)$ \\
5 & Columbia Univ & $14381(5)$ & $882(4)$ & $16.3(6)$ \\
6 & Univ Calif Los Angeles & $11802(6)$ & $741(6)$ & $15.9(8)$ \\
7 & Univ Texas & $11322(7)$ & $650(8)$ & $17.4(3)$ \\
8 & Univ Calif San Diego & $9942(8)$ & $716(7)$ & $13.9(10)$ \\
9 & Univ Penn & $9029(9)$ & $565(9)$ & $16.0(7)$ \\
10 & Duke Univ & $8830(10)$ & $517(10)$ & $17.1(4)$ \\
\hline
\end{tabular}

cited more often than others (see Table 7 for European institutions). The rankings of the institutions were broadly confirmed when the various subdivisions were combined.

HistCite does not provide direct information about flow of citations among different countries, nor has information on self-citation rates. Therefore, we collected this information manually from a stratified sample of 1,000 articles.

As shown on Table 8 , the selected 1,000 records were cited on 3504 occasions. Seventy-one per cent $(n=2,488)$ of citations came from the USA and $29 \%(n=1,016)$ from Europe. We found that Americans cite Americans more often $(50 \%, \mathrm{n}=1,252)$ and Europeans cite more European papers $(59 \%, \mathrm{n}=596)\left(\chi^{2}=336\right.$, d.f. $\left.=1, \mathrm{p}<0.001\right)$. Both Americans and Europeans receive citations from the rest of the world less often than from their own continent $\left(n=443,18 \%\right.$ and $n=193,18 \%$ respectively; $\chi^{2}=334$, d.f. $=2, \mathrm{p}<0.001$; Table 8).

When counting separately for UK publications $(n=693)$, we found that British publications more often cited other Europeans (30\%), whilst cited American (22\%) and British

Table 5 Rankings of European research institutions ordered by total number of citations (total global citation score, TGCS) (ranking in brackets)

\begin{tabular}{lllll}
\hline$\#$ & European Centre & TGCS & Records & Citations/paper \\
\hline 1 & Kings Coll/loP & $16730(1)$ & $1346(1)$ & $12.4(7)$ \\
2 & Univ Oxford & $6497(2)$ & $352(4)$ & $18.5(1)$ \\
3 & Univ Cambridge & $6270(3)$ & $340(6)$ & $18.4(2)$ \\
4 & Univ Munich & $6010(4)$ & $651(2)$ & $9.2(9)$ \\
5 & UCL & $4660(5)$ & $407(3)$ & $11.5(8)$ \\
6 & Univ Manchester & $3912(6)$ & $301(7)$ & $13.0(6)$ \\
7 & Univ Utrecht & $3209(7)$ & $230(8)$ & $14.0(5)$ \\
8 & Karolinska Inst & $3151(8)$ & $342(5)$ & $9.2(10)$ \\
9 & Maastricht Univ & $2799(9)$ & $193(9)$ & $14.5(4)$ \\
10 & Vrije Univ Amsterdam & $2750(10)$ & $170(10)$ & $16.2(3)$ \\
\hline
\end{tabular}


Table 6 Rankings of UK research institutions by citations received ordered by total number of citations received (total global citation score, TGCS) (ranking in brackets)

\begin{tabular}{lllll}
\hline$\#$ & UK Institution & TGCS & Records & Citations/paper \\
\hline 1 & $\begin{array}{l}\text { Kings College } \\
\text { London/Institute } \\
\text { of Psychiatry }\end{array}$ & $16730(1)$ & $1346(1)$ & $12.4(7)$ \\
2 & Univ Oxford & $6497(2)$ & $352(3)$ & $18.5(2)$ \\
3 & Univ Cambridge & $6270(3)$ & $340(4)$ & $18.4(3)$ \\
4 & University College & $4660(4)$ & $407(2)$ & $11.5(8)$ \\
& London & & & \\
5 & Univ Manchester & $3912(5)$ & $301(5)$ & $13.0(5)$ \\
6 & Univ Bristol & $2592(6)$ & $181(6)$ & $14.3(4)$ \\
7 & Univ Edinburgh & $2167(7)$ & $171(7)$ & $12.7(6)$ \\
8 & Univ Southampton & $2068(8)$ & $111(10)$ & $18.6(1)$ \\
9 & Univ Newcastle & $1446(9)$ & $135(9)$ & $10.7(9)$ \\
& Upon Tyne & & & \\
10 & Univ London Imperial & $1355(10)$ & $144(8)$ & $9.4(10)$ \\
\hline
\end{tabular}

(23\%) records equally often. UK articles constituted only $6 \%$ of the American and 17\% of other European citations.

We also explored numbers of self-citations. From the total of 3,504 citations that our 1,000 records received, $710(20 \%)$ were self-citations. We found no difference between the self-citation practices of the Americans (20\% of their citations were self-citations) and the Europeans (21\% were self-citations) $\left(x^{2}=0.001\right.$, d.f. $\left.=1, p=0.974\right)$. We also

Table 7 Rankings of European research institutions by subdivision ordered by total number of citations received (total global citation score, TGCS) (ranking in brackets)

\begin{tabular}{lllll}
\hline$\#$ & Institutions & TGCS & Records & Citations/paper \\
\hline 1 & $\begin{array}{l}\text { Kings College } \\
\text { London/Institute } \\
\text { of Psychiatry }\end{array}$ & $9130(1)$ & $718(1)$ & $12.7(7)$ \\
2 & $\begin{array}{l}\text { Univ Cambridge, Dept } \\
\text { Psychiat/Addenbrokes } \\
\text { Hospital }\end{array}$ & $4210(2)$ & $196(3)$ & $21.5(3)$ \\
3 & $\begin{array}{l}\text { Univ Oxford, Dept } \\
\text { Psychiat/Warneford } \\
\text { Hospital }\end{array}$ & $4026(3)$ & $173(4)$ & $23.3(1)$ \\
4 & $\begin{array}{l}\text { Univ Munich, Dept } \\
\text { Psychiat }\end{array}$ & $3302(4)$ & $292(2)$ & $11.3(8)$ \\
5 & $\begin{array}{l}\text { Inst Psychiat, Div } \\
\text { Psychol Med }\end{array}$ & $2212(5)$ & $124(5)$ & $17.8(5)$ \\
6 & $\begin{array}{l}\text { Univ Utrecht, Med Ctr } \\
7\end{array}$ & $1831(6)$ & $101(7)$ & $18.1(4)$ \\
Univ Cambridge, Dept & $1516(7)$ & $68(10)$ & $22.3(2)$ \\
8 & $\begin{array}{l}\text { Expt Psychol } \\
\text { Maastricht Univ, Dept }\end{array}$ & $1371(8)$ & $77(9)$ & $17.8(6)$ \\
9 & $\begin{array}{l}\text { Psychiat \& Neuropsychol } \\
\text { Univ Amsterdam, Acad }\end{array}$ & $1097(9)$ & $100(8)$ & $11.0(9)$ \\
10 & $\begin{array}{l}\text { Med Ctr } \\
\text { Leiden Univ, Med Ctr }\end{array}$ & $1056(10)$ & $103(6)$ & $10.3(10)$ \\
\hline
\end{tabular}

found that UK researchers were less likely to self-cite compared to all other countries, only $15 \%$ of their citations were self-citations $\left(x^{2}=8.7\right.$, d.f. $\left.=1, p=0.032\right)$.

In addition, we investigated how many records of the 3,504 publications were international research collaborations and found that $22 \%(\mathrm{n}=755)$ were collaborations between two or more countries.

In a sensitivity analysis, we combined Canada and the US to make North America and we found no material differences in citing papers from one's own continent $\left(\mathrm{X}^{2}=314\right.$, d.f. $\left.=1, \mathrm{p}<0.001\right)$ and in self-citation practices $\left(X^{2}=0.01\right.$, d.f. $\left.=1, p=0.919\right)$ compared with the above analysis (Table 9).

With regards to subject trends we found that articles focusing on treatment (including key words such as therapy, care, and management) were the most published $(\mathrm{n}=8,737)$. In terms of diagnosis, schizophrenia-related topics had the most publications ( $\mathrm{n}=5,855$ records) and were the most cited (TGCS $=51,842)$. Articles on depressi* $(n=5,120)$, together with articles on bipolar $(\mathrm{n}=2,185)$ and cogniti* $(\mathrm{n}=2,098)$ were also common keywords for articles.

\section{Discussion}

Journal impact factors and citation practices are increasingly used in the evaluation of research productivity and quality in medicine and other fields. In psychiatry, there have been bibliometric studies on scientific productivity focusing on specific subspecialties and the most popular research areas within them [5-11], on individual institutions [14], the contribution of different countries $[8,17]$, practices [18] and early recognition of high quality researchers [19]. However, to our knowledge, there has not been an overall examination of citation practices in psychiatry and clinical neurosciences.

This report presents the findings of research productivity across countries and institutions by tracking citations numbers and rates in psychiatry and related neuroscience. We examined 51,072 records that produced 375,962 citations during 2004-2009. There are two main findings. First, across countries, the findings underscore the dominance of US research in these fields. In relation to citation counts, US research produced more citations than the next nine most productive countries combined. This dominance was less obvious in relation to citation rates (citations per publication), although there appeared to be large differences between countries. One notable difference was that between Germany and the Netherlands, where citation rates differ two-fold (citations per publication 5.0 and 11.4 respectively). Second, within countries, there was a disparity in the top 10 most productive institutions depending on whether the number of publications, their citations, or their citation rate was counted. In other words, institutional research impact appears to differ markedly, depending on what output was used. 
Table 8 Citations received by country in a subgroup of 1000 articles originated from USA $(n=500)$ and Europe $(\mathbf{n}=\mathbf{5 0 0 )}$

\begin{tabular}{llllll}
\hline & USA & Europe & Rest of the World & Anonymous & Total citations $(\mathbf{n}=\mathbf{3 5 0 4})$ \\
\hline USA & $1240(0.50)$ & $712(0.29)$ & $443(0.18)$ & $88(0.03)$ & $2488(0.71)$ \\
Europe & $199(0.20)$ & $596(0.59)$ & $193(0.18)$ & $28(0.03)$ & $1016(0.29)$ \\
\hline
\end{tabular}

Note: Columns are the countries from which citation donors are based; rows are the countries which receive citations. The 1000 articles considered received 3504 citations.

Our findings may have implications for the development of research environments and their impact on productivity. The extent to which language, research governance, and national funding determine these differences needs further examination. The UK, in particular, has spent considerable resources developing a model of peer review that determines research funding for many years. We found differences in institutional impact by total numbers of records, citations, and citations per article. When applied to funding decisions this could lead to large differences in core funding for these research institutions. A final observation is the relative under-representation on non-European and non-American research groups in this field, a problem apparent in wider science [3]. This observation is consistent with other research on global representation in high impact psychiatric research, showing that psychiatric research published in high impact psychiatric journals was generated mainly in regions that represented only a small part of world's population [4].

In a sub-study, we tracked citations between countries and self-citation rates. We found that citation rates appeared to be broadly distributed according to article productivity. There are two possible implications of this. First, there is a certain and understandable preference in psychiatry and clinical neurosciences for research from an author's own country that can be found equally on both sides of the Atlantic. This may be explained by the author's deciding on citing material from their national journals [17], which would tend to be populated by local researchers, rather than any other reason. Second, researchers in the field need to consider whether this potentially limits the interpretation and generalizability of their work. Interestingly, we found no strong differences in self-citation rates between Europe and US.

We performed a sensitivity analysis to investigate whether the results of our sub-study applied to North America (Canada and US). We looked at 1000 articles, 500 from the North America (US and Canada) and 500 from Europe. We found no material differences in citation practices (self-citation, preferences in research from an author's own continent) compared with the results of our sub-study.

In the same sub-study we found that $22 \%(\mathrm{n}=755)$ of the citations were collaborations between two or more countries. Future research could explore whether researchers that collaborate internationally tend to cite other international collaborations.

One strength of the current report is that we have used a large sample of articles from a broad range of relevant journals - 51,072 articles published in 50 indexed psychiatric and clinical neurosciences journals during a five-year period (2004-2009). However, there are a number of important limitations. First we collected our data from Web of Science, hence we will be missing the articles published in journals excluded from it. We carefully avoided to compare the Web of Science with other databases used for citation analysis, such as the Scopus or the Google Scholar, as they are all using different sources to generate their data, hence are not directly comparable. Similarly, research on which database is preferable remains controversial [32,34,35]. We limited our study to the top 50 journals in psychiatry, which

Table 9 Sensitivity analysis for citations received by country in a subgroup of 1000 articles originated from North America $(n=500)$ and Europe $(n=500)$

\begin{tabular}{lllll}
\hline & North America & Europe & Rest of the world & Anonymous \\
\hline North America & $1294(0.54)$ & $675(0.28)$ & $324(0.14)$ & $84(0.04)$ \\
Europe & $248(0.24)$ & $596(0.59)$ & $144(0.14)$ & $28(0.03)$ \\
\hline
\end{tabular}

Note: Columns are the countries from which citation donors are based; rows are the countries which receive citations. The 1000 articles considered received 3393 citations.

We found that North Americans cite North Americans more often $(54 \%, n=1,294)$ and Europeans cite more European papers $(59 \%, n=596)\left(x^{2}=314\right.$, d.f. $=1$, $\mathrm{p}<0.001)$. Both Americans and Europeans receive citations from the rest of the world less often than from their own continent $\left(x^{2}=314\right.$, d.f. $\left.=2, p<0.001\right)$. We also explored numbers of self-citations. From the total of 3,393 citations that our 1,000 records received, 691 (20\%) were self-citations. We found no difference between the self-citation practices of the Americans ( $20 \%$ of their citations were self-citations) and the Europeans $\left(21 \%\right.$ were self-citations) $\left(x^{2}=0.01\right.$, d.f. $=1, p=0.919)$.

In addition, we investigated how many records of the 3,393 publications were international research collaborations and found that $22 \%$ ( $=746)$ were collaborations between two or more countries.

The above results are similar to those between US and Europe (Table 8). It seems that considering North America (US and Canada) rather than US alone does not materially alter our conclusions. 
would miss the leading journals in important related fields such as nursing, social work and clinical psychology. Alternative approaches to selecting journals can be considered in future research. Another limitation is that we relied, for practical reasons, on the affiliation of the corresponding author to determine the location of the author and subsequent citation rates of their institution. We might therefore have underestimated the productivity of some collaborating institutions and countries. We did not explore the citation practices between authors and their scientific network, and were unable to examine how this would affect the flow of citations among researchers [36]. In our methods, we looked at all countries but decided to limit our results to the top 10 in research productivity. This resulted in countries represented in this paper to be predominantly Western. This is likely to change over time as some countries' research infrastructure (such as China) develops. A large number $(n=4855)$ of articles could not be categorised by country. This is an important limitation of using a web-based data base to collect our data. It is not certain whether the articles that we could not categorise would be disproportionately from one country, and therefore the effect on the results is not known. In our sub-study we looked at 1000 articles, 500 from the US and 500 from Europe. This was an arbitrary decision based on where the main concentrations of research-active universities were. Thus this sub-study was limited in not being to assess important research countries such as Canada or Australia. Future work should include other countries such as Canada, Australia, and China, as their impact is increasingly recognised. We also used the oldest articles for the sub-study. It is possible that the trends are changing or will change in the future, especially with regards to the recent appearance of eastern countries in the citation map. Finally, we included all types of publications and this can be a limitation of our study as some types of articles attract more citations than others.

\section{Conclusions}

In summary, in this large study of scientific output and citation trends in psychiatry and clinical neuroscience, we have found large differences between and within countries in terms of their research productivity. The choice of output will be important in determining how this translates into decisions about resource allocation for research.

\section{Competing interests}

The authors declare that they have no competing interests.

\section{Authors' contributions}

Conceived and designed the research: AI SF KE. Performed collection of data: Al NR. Analysed the data: AI SF KE. Wrote the paper: AI SF KE NR. All authors read and approved the final manuscript.

\section{Acknowledgements}

The authors are grateful to Professor Paul Harrison for his suggestions. Dr Artemis Igoumenou is supported by a NIHR Clinical Lectureship. Prof Seena Fazel is supported by a Wellcome Trust Senior Research Fellowship.

\section{Author details}

${ }^{1}$ Violence Prevention Research Unit, Wolfson Centre of Preventive Medicine, Barts and the London School of Medicine and Dentistry, Queen Mary, University of London, Garrod Building, Turner Street, London E1 2AD, England. 'Department of Psychiatry, Warneford Hospital, University of Oxford, Oxford, England. ${ }^{3}$ Bodlean Library, Oxford, England.

Received: 12 July 2014 Accepted: 10 November 2014

Published online: 06 December 2014

\section{References}

1. King D: The scientific impact of nations. What different countries get for their research spending. Nature 2004, 430:311-316.

2. Kulkarni AV, Busse JW, Shams I: Characteristics associated with citation rate of the medical literature. PLoS One 2007, 2(5):e403. doi:10.1371/ journal.pone.0000403.

3. Patel V, Sumathipala A: International representation in psychiatric literature: survey of 6 leading journals. Br J Psychiatry 2001, 178:406-409.

4. Zhang M, Hedges DW, Brown BL: Global representation in psychiatric research. Int Psychiatry 2012, 9(4):94-96.

5. Theander SS, Wetterberry L: Schizophrenia in Medline 1950-2006: a bibliometric investigation. Schizophr Res 2010, 118(1):279-284.

6. Lòpez-Münoz F, Vieta E, Rubio G, Garcia-Garcia P, Alamo C: Bipolar disorder as an emerging pathology in the scientific literature: a bibliometric approach. $J$ Affect Disord 2006, 92(2):161-170.

7. Lipsman N, Lozano AM: The most cited works in major depression: the 'citation classics'. J Affect Disord 2011, 134(1-3):39-44.

8. Kieling C, Hernan H, Patel V, Tyrer P, Mari Jj: A global perspective on the dissemination of mental health research. Lancet 2009, 22(374(9700)):1500.

9. Licinio J: Molecular psychiatry: the highest immediacy index in the field of psychiatry. Mol Psychiatry 2006, 11(4):324.

10. Lòpez-Münoz F, Alamo C, Rubio G, Garcia-Garcia P, Martin-Agueda B, Cuenca E: Bibliometric analysis of biomedical publications on SSRI during 1980-2000. Depress Anxiety 2003, 18(2):95-103.

11. Kecmanovic D, Hadzi-Pavlovic D: Psychiatric journals as the mirror of the dominant psychiatric model. The Psychiatrist 2010, 34:172-176.

12. Maunder R: Using publication statistics for evaluation in academic psychiatry. Can J Psychiatry 2007, 52(12):790-797.

13. Diaz-Moran S, Tobena A: Research contributions of Spanish psychiatry (2004-2009): a bibliometric analysis of university department. Actas Esp Psiquiatr 2011, 39(5):294-301.

14. Koshinen J, Isohanni M, Paajala $H$, Jääskeläinen $E$, Nieminen $P$, Koponen $H$, Tienari P, Miettunen J: How to use bibliometric methods in evaluation of scientific research? An example from Finnish schizophrenia research. Nord J Psychiatry 2008, 62(2):136-143.

15. Haslam N, Lusher D: The structure of mental health research: networks of influence among psychiatry and clinical psychology journals. Psychol Med 2011, 41(12):2661-2668.

16. Walter G, Hunt G, Soh N, Cleary M, Martin A: Fifty years and counting: celebrating citations to the journal. J Am Acad Child Adolesc Psychiatry 2011, 50(7):636-639.

17. Baethge $C$ : The production and recognition of psychiatric original articles published in languages other than English. BMC Psychiatry 2013, 13:102. doi:10.1186/1471-244X-13-102.

18. Nieminen P, Rucker G, Miettunen J, Carpenter J, Schumacher M: Statistically significant papers in psychiatry were cited more often than others. J Clin Epidemiol 2007, 60(9):939-946.

19. Jacob JH, Lehrl S, Wolfram Henkel A: Early recognition of high quality researchers of the German psychiatry by worldwide accessible bibliometric indicators. Scientometrics 2007, 73(2):117-136. doi:10.1007/ s11192-006-1729-x.

20. Sorensen AA: Alzheimer's disease research: scientific productivity and impact of the top 100 investigators in the field. J Alzheimers Dis 2009, 16(3):451-465.

21. Cox BJ, Wessel I, Norton GR, Swinson RP: Citation patterns in anxiety disorders research in 14 journals: 1990-1991. Am J Psychiatry 1994, 151(6):933-936. 
22. Derrick GE, Haynes A, Chapman S, Hall WD: The association between four citation metrics and peer rankings of research influence of Australian researchers in six fields of public health. PLoS One 2011, 6(4):e18521. doi:10.1371/journal.pone.0018521.

23. Barak Y, Philpot M, Levy R: Citation patterns in the International Journal of Geriatric Psychiatry: cultural ethnocentrism revisited? In J Geriatr Psychiatry 1995, 10:1015-1018.

24. West $R$, Mcllwaine A: What do citation counts count for in the field of addiction? An empirical evaluation of citation counts and their link with peer ratings of quality. Addiction 2002, 97:501-504.

25. Pastercamp G, Rotmans Jl, DeKleijn DVP, Borst C: Citation frequency: a biased measure of research impact significantly influenced by the geographical origin of research articles. Scientometrics 2007, 70(1):153-165.

26. Campbell FM: National bias: a comparison of citation practices by health professionals. Bull Med Lib Assoc 1990, 78(4):376-382.

27. Kulkarni AV, Aziz B, Shams I, Busse JW: Author self-citation in the general medicine literature. PLoS One 2011, 6(6):e20885. doi:10.1371/journal. pone.0020885.

28. Garfield E, Paris SW, Stock WG: HistCite ${ }^{\mathrm{TM}}$ : a software tool for informetric analysis of citation linkage. Inf Technol Sci 2006, 57(8):391-400.

29. Hirsch JE: An index to quantify an individual's scientific research output. Proc Natl Acad Sci U S A 2005, 102(46):16569-16572. doi:10.1073/ pnas.0507655102.

30. Egghe L: Theory and practise of the g-index. Scientometrics 2006, 69(1):131-152. doi:10.1007/s11192-006-0144-7.

31. Carleton RN, Parkerson HA, Horswill SC: Assessing the publication productivity of clinical psychology professors in Canadian Psychological Association-Accredited Canadian Psychology Departments. Can Psychol 2012, Advance online publication. doi:10.1037/a0027731.

32. Jacso P: As we may search-comparison of major features of the Web of science, Scopus, and Google scholar citation-based and citation-enhanced databases. Curr Sci 2005, 89(9):1537-1547.

33. Kulkarni AV, Aziz B, Shams I, Busse JW: Comparisons of citations in Web of science, Scopus, and Google scholar for articles published in general medical journals. JAMA 2009, 302(10):1092-1096.

34. Bakkalbasi N, Bauer K, Glover J, Wang L: Three options for citation tracking: Google scholar, Scopus and Web of science. Biomed Digit Libr 2006, 3(7). doi:10.1186/1742-5581-3-7.

35. Meho LI, Yang K: Impact of data sources on citation counts and rankings of LIS faculty: Web of science vs. Scopus and Google scholar. J Am Soc Inf Sci Technol 2007, 58(13):2105-2125. doi:10.1002/asi.20677.

36. Wallace $M L$, Larivière $V$, Gingras $Y: A$ small world of citations? The influence of collaboration networks on citation practices. PLoS One 2012, 7(3):e33339. doi:10.1371/journal.pone.0033339.

doi:10.1186/s12888-014-0332-6

Cite this article as: Igoumenou et al: Geographic trends of scientific output and citation practices in psychiatry. BMC Psychiatry 2014 14:332.

\section{Submit your next manuscript to BioMed Central and take full advantage of:}

- Convenient online submission

- Thorough peer review

- No space constraints or color figure charges

- Immediate publication on acceptance

- Inclusion in PubMed, CAS, Scopus and Google Scholar

- Research which is freely available for redistribution

Submit your manuscript at www.biomedcentral.com/submit
C Biomed Central 